\title{
Reactor de lecho fluidizado de dos zonas con membrana permeable al hidrógeno para deshidrogenación catalítica de propano
}

\author{
J.A. Medrano ${ }^{1}$, I. Julián ${ }^{1}$, F. García-García ${ }^{2}$, K. Li ${ }^{2}$, J. Herguido ${ }^{1}$, M. Menéndez ${ }^{1}$, \\ ${ }^{I}$ Catalysis, Molecular Separation and Reactor Engineering Group (CREG) \\ Instituto de Investigación en Ingeniería de Aragón (I3A) \\ Universidad de Zaragoza, Mariano Esquillor s/n, 50018, Zaragoza, Spain. \\ Tel. +34-976762707, Fax +34-976762043, e-mail: 550765@unizar.es \\ ${ }^{2}$ Chemical Engineerng Department \\ Imperial College London \\ South Kensignston Campus \\ London SW7 2AZ, United Kingdom
}

\begin{abstract}
El aumento en el consumo de propileno ha favorecido el desarrollo de nuevos procesos para su producción, siendo la deshidrogenación catalítica de propano una alternativa muy interesante. Sin embargo, este proceso lleva asociadas varias limitaciones: reacción endotérmica y limitada por el equilibrio termodinámico, existencia de reacciones secundarias que disminuyen la selectividad a propileno, y desactivación del catalizador por formación de coque. El reactor de lecho fluidizado de dos zonas con membrana permeable al hidrógeno se presenta como un dispositivo capaz de solventarlas todas en un único espacio físico, complementándolo con un catalizador ( $\left.\mathrm{Pt}-\mathrm{Sn} / \mathrm{MgAl}_{2} \mathrm{O}_{4}\right)$ que reduce la formación de reacciones secundarias. En este sistema existen dos puntos de alimentación, generánose dos zonas de diferente atmósfera: una zona superior de reacción, y una inferior de regeneración con atmósfera oxidativa. Así, en la zona superior se produce el propileno y se desactiva el catalizador, el cual desciende (por el fenómeno de fluidización) a la zona de regeneración donde se reactiva por combustión del coque depositado, aportando un calor directo al sistema endotérmico. Por ello se consigue un sistema cícliclo de reacción-regeneración que permite mantener un estado estacionario del proceso, logro inviable en los reactores tradicionales. Además el hidrógeno formado en reacción se separa a través de una membrana de paladio, modificando y solventando la limitación del equilibrio termodinámico hacia una mayor formación de productos y aumentando el rendimiento del proceso. Así, este sistema supone un claro ejemplo de intensificación de procesos.
\end{abstract}

